\title{
Factors that ameliorate or aggravate spasmodic torticollis
}

\author{
Marjan Jahanshahi
}

\begin{abstract}
A sample of 72 patients with adult onset torticollis were asked to complete a checklist to indicate how a list of situations and activities affected the severity of their torticollis. Stress and self consciousness were reported as aggravating factors by more than $80 \%$ of the sample, whereas walking, fatigue, and carrying objects were noted as exacerbators by over $70 \%$ of the patients. For more than $40 \%$ of the sample, torticollis improved in the supine position, by relaxation, sleep, and lying on the side. However, the last four factors also worsened the head deviation in $16 \%$ to $25 \%$ of the patients. Use of a "geste antagoniste" to maintain the head in the body midline, was reported by $64(88.9 \%)$ of the patients, which was still effective in correcting head position in $47 \%$. The sensitivity of torticollis to social and emotional factors can be best explained in terms of a possible link between extrapyramidal and affective disorders through overlapping changes in catecholamine metabolism. The worsening of torticollis with peripheral motor activity (walking, running, writing) or its improvement with changes in body posture or with the geste antagoniste is best viewed in terms of alterations of peripheral proprioceptive feedback or central corollary discharge provoked by the motor output or command.
\end{abstract}

(F Neurol Neurosurg Psychiatry 2000;68:227-229)

Keywords: spasmodic torticollis; geste antagoniste; amelioration; aggravation

Department of Clinical Neurology, Institute of Neurology, The National Hospital for Neurology and

Neurosurgery, Queen

Square, London,

WC1N 3BG, UK

M Jahanshahi

Correspondence to:

Dr M Jahanshahi

email

m.jahanshahi@ion.ucl.ac.uk

Received 8 July 1999 and in revised form

27 September 1999

Accepted 21 October 1999 $a l^{11}$ ), or a non-homogeneous sample (Patterson and Little $\left.{ }^{10}\right)$.

Many patients with torticollis develop and use "tricks" to reduce or eliminate the abnormal head posture. These tricks are called "geste antagoniste". An example of a geste antagoniste is the patient moving a hand to touch his chin or the back of his neck, a movement that will effectively straighten the head position. The mechanism of action of the geste antagoniste is unknown. At various times in the history of torticollis, the geste antagoniste has been considered as confirmatory evidence for the hysterical nature of the illness, ${ }^{12}$ whereas at other times its mechanism of action has been interpreted in various physiological terms. ${ }^{5613}$

The absence of consistent results across the studies that have examined the effect of various factors on the severity of torticollis may partly be related to differences in sample characteristics. Given the heterogeneous nature of the disorder, the influence of situational and behavioural factors can only be reliably assessed in a large and homogeneous sample of patients with torticollis. This was the aim of the present study.

\section{Method}

SUBJECTS

The sample consisted of 72 cases of adult onset idiopathic torticollis ( 35 men and 37 women). The sample was homogenous in several respects. Firstly, all cases were idiopathic as those with secondary torticollis were excluded. Secondly, for all patients torticollis had been the initial presenting symptom. Thirdly, the sample was limited to cases with adult onset torticollis, with onset after the age of 20 . The mean age of onset of torticollis was 43.5 (SD 10.3) years, with a mean duration of illness of 7.7 (SD 5.9) years. The mean age was 51.2 (SD 10.4) years. Torticollis had remained focal in 49 cases $(68.1 \%)$, and had spread to other parts of the body in 23 patients $(31.9 \%)$. Forty patients $(55.6 \%)$ had pure retrocollis. In the remaining 25 patients $(34.7 \%)$, the head deviation was a combination of turn/tilt and forward flexion or backward extension. Torticollis was clonic in $52(72.2 \%)$ and tonic in 20 $(27.8 \%)$ of the patients. 
Table 1 The factors that improved, aggravated; or had no effect on torticollis and the percentage of patients reporting each effect

\begin{tabular}{lllc}
\hline Factor & \%Worse & $\%$ Unchanged & $\%$ Better \\
\hline Exacerbating factors: & & & \\
Stress & 85.1 & 14.9 & 0.0 \\
Self consciousness & 84.8 & 12.1 & 3.0 \\
Walking & 74.6 & 18.3 & 7.0 \\
Fatigue & 74.2 & 21.2 & 4.5 \\
Carrying objects & 73.1 & 22.4 & 4.5 \\
Writing & 68.7 & 26.9 & 4.2 \\
Running & 61.5 & 19.2 & 19.2 \\
Social situations & 58.6 & 31.0 & 10.3 \\
Emotion & 55.6 & 41.3 & 3.2 \\
Time of day: & & & \\
$\quad$ Afternoon & 50.8 & 37.7 & 11.5 \\
$\quad$ Evening & 53.1 & 34.4 & 12.5 \\
$\quad$ Cold & 53.1 & 45.3 & 1.6 \\
Ameliorating factors: & & & \\
Lying on back & 21.0 & 25.8 & 53.2 \\
Relaxation & 23.5 & 29.4 & 47.1 \\
Sleep & 25.4 & 28.8 & 45.8 \\
Lying on side & 16.1 & 38.7 & 45.2 \\
$\quad$ Geste antagoniste & 0.0 & 53.0 & 47.0 \\
Factors with no effect: & & & \\
Menstrual cycle & & & \\
$\quad$ Menstrual & 25 & 68.7 & 6.3 \\
$\quad$ Intermenstrual & 18.8 & 68.7 & 12.5 \\
$\quad$ Premenstrual & 37.5 & 62.5 & 25.4 \\
Heat & 19.0 & 55.6 & 17.6 \\
Alcohol & 29.4 & 52.9 & 39.3 \\
Distraction & 16.4 & 44.3 & \\
Time of day & & & \\
$\quad$ On awakening & 31.7 & 36.5 & \\
\hline
\end{tabular}

PROCEDURE

From a survey of the literature and direct questioning of a sample of 10 patients with torticollis, a list of common factors affecting the severity of the head deviation or movements was compiled. This "effect of stimuli" checklist was completed by 72 patients participating in a study on the natural history and the pschosocial sequalea of the illness. Patients were asked to indicate the extent to which their torticollis was affected by various situational and behavioural factors, by ticking the appropriate response column. The response columns were: worse, unchanged, better, or don't know. The patients were also asked to indicate whether they had ever used a geste antagoniste to normalise head position, and if so, whether it was still effective.

\section{Results}

The factors that were reported by the patients to improve, or exacerbate, or have no effect on their torticollis are presented in the table, together with the percentage of the patients who noted each effect (better, unchanged, worse). The association between the direction or form of head deviation and the reported effect (better, unchanged, worse) was not significant for any of the factors considered.

\section{Discussion}

The present results are in general agreement with previous studies. ${ }^{4}{ }^{10} 11$ In the present larger and more homogenous sample of patients with adult onset idiopathic torticollis, there is a greater consensus on the factors that exacerbate torticollis. Stress and self consciousness were reported as aggravating factors by more than $80 \%$ of the sample, whereas walking, fatigue, and carrying objects were noted as exacerbators by over $70 \%$ of the patients. For more than $40 \%$ of the sample, torticollis improved in the supine position, by relaxation, sleep, and lying on the side. However, the last four factors also worsened the head deviation in $16 \%$ to $25 \%$ of the patients. Use of a geste antagoniste to maintain the head in the body midline, was reported by $64(88.9 \%)$ of the patients, which was still effective in correcting head position in $47 \%$.

The effect of three factors on torticollis are of special interest: different phases of the menstrual cycle, alcohol, and morning relief. Menstrual phase related worsening of their disorder has been noted in female patients with Parkinson's disease, ${ }^{14}$ and dominantly inherited myoclonic dystonia. ${ }^{15}$ The greatest proportion of the premenopausal women in this sample reported no change in their torticollis during the different phases of the menstrual cycle, although worsening of torticollis in the premenstrual and menstrual phases of the cycle was respectively noted by $37.5 \%$ and $25 \%$.

The present results on the effect of alcohol on torticollis are not consistent with the findings of Biary and Koller ${ }^{16}$ who reported improvement in head deviation in five of seven patients with torticollis $(71 \%)$ after an intravenous injection of ethanol. In the present sample, alcohol was reported as an ameliorating factor only by $17.6 \%$. In fact, alcohol aggravated the head deviation in $29.4 \%$ of the patients, and had no particular effect for most $(52.9 \%)$. Differences in methodology may be partly responsible for the divergent results of the two studies.

A class of dystonia with marked diurnal variation characterised by freedom from dystonic movements and postures in the morning and worsening of dystonia in the afternoon and evening has been described by Segawa et al. ${ }^{17}$ Improvement or relief from torticollis on awakening in the mornings was experienced by $31.5 \%$ of the present sample of patients with adult onset idiopathic torticollis. The relation of this to the subclass of dystonia with diurnal variation of Segawa et $a l^{17}$ which is often coupled with features of parkinsonism and responsiveness to levodopa, bromocritpine, or anticholinergic drugs ${ }^{18}$ remains unclear.

The sensitivity of torticollis to social and emotional factors and motor and postural influences has in the past been regarded as evidence for the psychogenic origin of the disorder. We have previously provided evidence $^{19-21}$ against a psychogenic aetiology in torticollis. Instead, we have suggested an alternative formulation that views the depression encountered in a proportion of the patients as a reaction to the disability and social embarrassment associated with the postural disfigurement. ${ }^{22-25}$ Similarly, with regard to factors that exacerbate or ameliorate torticollis, although the precise mechanisms are unknown, such influences are now subject to alternative and more plausible interpretations in biochemical or physiological terms. The exacerbation of torticollis in affect or stress inducing situations can be explained in terms of a possible link between extrapyramidal and affective disorders through overlapping 
changes in CNS catecholamine metabolism. ${ }^{26}$ Similarly, the worsening of torticollis with peripheral motor activity (walking, running, writing), or its improvement with changes in body posture (supine position), or with the geste antagoniste is best viewed in terms of alterations of peripheral proprioceptive feedback or central corollary discharge provoked by the motor output or command. Although feasible, these alternative interpretations are also speculative and require direct examination through further investigation.

1 Barre JA. Le torticolis spasmodique. Rev Neurol 1929;51:984-1013.

2 Meige H. Remarques personnelles sur les torticolis spasmodiques. Rev Neurol 1929;1:1013-21.

3 Herz E, Glaser GH. Spasmodic torticollis. II. Clinical evaluation. Archives of Neurology and Psychiatry 1949;49:381-9. 4 Tibbetts RW. Spasmodic torticollis. If Psychosom Res 1971;15:461-9.

5 Tournay A, Paillard J. Etude electromyographic de mouvements volontaires et involontaires du cou. Rev Neurol 1952 86:685-7.

6 Podivinsky F. Torticollis. In: Vinken RA, Bryun GW, eds. Handbook of clinical neurology. Amsterdam: North-Holland, 1968;6:567-603.

7 Meares R, Lader M. Electromyographic studies in patients with spasmodic torticolllis. F Psychosom Res 1971;15:13-18

8 Matthews WB, Beasley P, Parry-Jones W, et al. Spasmodic torticollis: a combined clinical study. $\mathcal{F}$ Neurol Neurosurg Psychiatry 1978;41:485-92.

9 Rondot P, Jedynak CP, Ferey G. Le torticolis spasmodique. Paris: Masson, 1981.

10 Patterson RM, Little SC. Spasmodic torticollis. $\mathcal{F}$ Nerv Ment Dis 1942;98:571-99.
11 van Hoof JJM, Horstink MWI, Berger HJC, et al. Spasmodic torticollis: the problem of pathophysiology and assessment. f Neurol 1987;234:322-7.

12 Brissaud E, Bauer M. Torticolis mental traite par la reeducation psychomotrice. Rev Neurol 1909;18:940-1.

13 Tournay A, Paillard J. Torticolis spasmodic et electromyographie. Rev Neurol 1955;93:347-55.

14 Quinn NP, Marsden CD. Menstrual-related fluctuations in Parkinson's disease. Mov Disord 1986;1:85-7

15 Quinn NP, Rothwell JC, Thompson PD, et al. Hereditary myoclonic dystonia, hereditary torsion dystonia and hereditary essential myoclonus: an area of confusion. $A d v$ Neurol 1988;50:391-401.

16 Biary N, Koller W. Effect of alcohol and dystonia. Neurology 1985;35:239-40.

17 Segawa M, Hosaka A, Miyagawa F, et al. Hereditary progressive dystonia with marked diurnal fluctuation. $A d v$ Neurol 1976;14:215-33.

18 Fahn S, Marsden CD, Calne DB. Classification and investigation of dystonia. In: Marsden CD, Fahn S, eds. Movement disorders. London: Butterworth, 1987;2:332-58.

19 Jahanshahi M, Marsden CD. Personality in torticollis: a controlled study. Psychol Med 1988;18:375-87.

20 Jahanshahi M, Marsden CD. Conversion "V" profiles in torticollis. Behavioural Neurology 1989;2:219-25.

21 Jahanshahi M. Personality in torticollis: changes across time. fournal of Personality and Individual Differences 1990;11: Fournal of 1 355-63.

22 Jahanshahi M, Marsden CD. Body concept, disability and depression in torticollis. Behavioural Neurology 1990;3: 117-31.

23 Jahanshahi M, Marsden CD. A longitudinal follow-up study of depression, disability and body concept in torticollis. Behavioural Neurology 1990;3:233-46.

24 Jahanshahi M. Psychosocial correlates of depression in torticollis. F Psychosom Res 1991;35:1-15.

25 Jahanshahi M, Marsden CD. Depression, disability and body concept in torticollis before and after treatment with botulinum toxin. F Neurol Neurosurg Psychiatry 1992;55: 229-31.

26 Vinken PJ, Bruyn WB. Handbook of clinical neurology diseases of the basal ganglia. Vol 6. Amsterdam: North-Holland, 1986. 